higher level to generate enough capacity. However, the Aim is that most emergency workers continue to do their own work in standard procedures, we also need more coordination, information management, transition of "stay and play" to "scoop and run" and deploying volunteers and citizens.

Aim: We developed the model practice-based, however, we have little big incidents. We feel the urgency to compare this practice to international knowledge.

Methods: The goal is twofold: validation of the starting points of our model, but also further improvement: speeding up the transport and treatment of patients, improvement of capacity, safety of the ambulance staff - especially with terrorist attacks or contamination, civil participation. We held the first survey on scientific literature in English, related to items in our prehospital assistance model. (the article is not yet published).

Results: The conclusion was, that scientific articles are rare, however, a lot of information is given about the practical course of incidents. Scientific research to explore these experiences is rare, partly due to a missing universal terminology on disaster medicine.

Discussion: We want to contribute to enlarging the scientific knowledge on large scale prehospital assistance. We expect that a lot of practical experience can be unlocked by bringing together experts in this field. We want to present the Dutch model, with a focus and invitation to compare this with the models in other countries, to compare experiences, to deepen them and to stimulate international research. We want to commit ourselves to facilitate this.

Prehosp Disaster Med 2019;34(Suppl. 1):s115-s116

doi:10.1017/S1049023X19002462

\section{Developing a Public Health Risk Assessment Toolkit for Mass Gatherings and Trialling for an International Multi-Sport Mass Gathering Event \\ Ms. Ellen Bloomer ${ }^{1}$, Tina Endericks ${ }^{1,2}$}

1. Public Health England, London, United Kingdom

2. WHO Collaborating Centre on Mass Gatherings and Global Health Security, London, United Kingdom

Introduction: Risk assessment for mass gatherings (MGs) is undertaken to enable public health authorities to systematically identify and assess the generic characteristics of an MG, which introduce or enhance particular threats and develop measures to reduce or mitigate these threats. The World Health Organization Collaborating Centres on Mass Gatherings and Global Health Security (WHO CCs) produced a comprehensive guide to MGs called "Public Health for Mass Gatherings: Key Considerations" (KC2). This is being converted into an eLearning resource. A public health risk assessment toolkit is being developed by the WHO CCs to complement and guide organizers in their planning process for the health risks associated with an MG event. Preparations for the Birmingham 2022 Commonwealth Games (BCG) are underway and it is important to involve a public health element in the planning for the BCG.

Aim: To develop a public health risk assessment toolkit for MGs and pilot it as part of the planning process for the BCG.
Methods: Based on $\mathrm{KC} 2$ principles, methods included developing and finalizing a public health risk assessment toolkit for MGs. This study also piloted the toolkit for the BCG.

Results: A toolkit will be developed. Key learning will be documented on how the toolkit can be improved. The pilot will identify the key public health risks for the BCG, and assess how to mitigate them.

Discussion: The development of this toolkit will be an innovative contribution to the resources available for those organizing MGs. It will support organizers to conduct risk assessments and thus maximize the potential for health from the event. Piloting the toolkit for the BCG is an opportunity for validating it, and provides valuable learning for its use in future events. It will support the risk assessment process for the BCG and share learning regarding the key risks for this event.

Prehosp Disaster Med 2019;34(Suppl. 1):s116

doi:10.1017/S1049023X19002474

\section{Developing an Educational Strategy for Delivering an E-learning Disaster Medicine Course for Undergraduate Students in US Medical Schools}

Dr. Michael Molloy ${ }^{1,2}$, Edmond Power ${ }^{2}$, A Prof. Gregory

R. Ciottone ${ }^{1,3}$

1. BIDMC Fellowship In Disaster Medicine, Boston, United States

2. University College Dublin, Belfield, Dublin, Ireland

3. Department of Emergency Medicine, Harvard Medical School, Boston, United States

Introduction: Disaster Medicine (DM) is a discipline arising from the marriage of emergency medicine and disaster management. The importance of DM has recently increased, with current wildfire situations throughout the world being examples of mass scale disasters with significant human morbidity and mortality. DM deals with preparedness, mitigation, response, recovery, and prevention of disasters (1).

Aim: To develop an educational strategy and reusable format for delivering undergraduate DM courses online. Man-made, weather-related, humanitarian, and technological disasters occur all around the globe annually, yet the majority of medical schools do not have an undergraduate DM program. This project developed an online course structure accessible to medical schools and students throughout the world.

Methods: Learning theories and models of learning were used to construct a course layout that encouraged students to be active learners, developed long-term retention strategies, and facilitated assessment for and of learning. This was accomplished through innovative educational modalities, including novel apps and external online resources. The course focuses heavily on outcome-based education with an emphasis on the development of applicable skills. Each lecture is divided into a series of learning objectives to allow students to master concepts sequentially, followed by questions to make use of the "testing effect" (2).

Results: Focused review of current medical education literature reveals that students learn best when given short, outcomefocused "mini-lectures" followed by low-stakes assessment and feedback. 
Discussion: Medical schools without trained DM staff now have access to expert online material developed by educationalists with a focus on skills and knowledge retention.

\section{References:}

1. Ciottone GR, Darling RG, Biddinger PD, Keim ME, Molloy MS. Ciottone's Disaster Medicine. Elsevier Health Sciences; 2015.

2. Larsen DP, Butler AC, Roediger HL. Test-enhanced learning in medical education. Med Educ. Wiley/Blackwell (10.1111); 2008 Oct;42(10):959-966.

Prehosp Disaster Med 2019;34(Suppl. 1):s116-s117

doi:10.1017/S1049023X19002486

\section{Developing Collaboration Quality Indicators for Major Incidents in an Underground Mine \\ Dr. Lina Gyllencreutz, Ms. Sofia Karlsson, Prof. Britt-Inger \\ Saveman \\ Disaster Medicine Center for Research and Development, Umeå, Sweden}

Introduction: The underground mining industry has one of the most hazardous industrial occupations, and requires an increased level of preparedness for injury incidents. The most important outcome for seriously injured victims is the reduction in morbidity and mortality. Receiving effective and timely care may mean the difference between life and death. However, mines are usually located in a rural area and the incident site may be deep underground which makes it an extraordinary challenge for the rescue services. A successful rescue response in an extraordinary milieu demands a high level of inter-organizational cooperation skills at the incident site.

Aim: To analyze statements of collaborate activities during a major incident exercise in the underground mine industry, essentially for patient outcome.

Methods: A Delphi technique was performed, asking opinions from experts in iterative rounds to generate, understand, and form consensus on group opinion around this complex issue. The experts were personnel from disaster medicine $(n=3)$, emergency and prehospital medicine $(\mathrm{n}=10)$, rescue service $(n=16)$, and mine industry $(n=9)$, all with operative command positions.

Results: Three iterative rounds were performed. The first round was conducted as a workshop to collect opinions about the most important inter-organization cooperation activities to optimize patient outcome from an injury incident in an underground mine. This resulted in 63 statements. The statements included information about: early alarm routines, collaborative support and efforts of early life-saving interventions, relevant resources and equipment, command and control room, and functions. In round two participants shared and communicated decisions about safety, situation awareness, and guidelines for response. All statements reached consensus among the experts in round three.

Discussion: These inter-organizational statements are considered important by experts, and could be used to evaluate collaboration in major incident exercises. Hence, the statements can also be quality indicators for reporting results from major incident management.

Prehosp Disaster Med 2019;34(Suppl. 1):s117

doi:10.1017/S1049023X19002498

\section{Development and Challenges of Japan DMORT (Disaster Mortuary Operational Response Team)} Association

Dr. Kazutoishi Kuboyama ${ }^{1}$, Dr. Kayoko Kurokawa ${ }^{2}$, Dr. Noriko Murakami ${ }^{3}$, Dr. Yasushi Nagasaki ${ }^{4}$,

Dr. Takashi Ukai ${ }^{5}$, Ms Tatsue Yamazaki,

Dr. Kazumasa Yoshinaga ${ }^{7}$

1. Kyoto Tachibana University, Nishinomiya, Japan

2. Ryukoku University, Kyoto, Japan

3. Japanese Red Cross Kobe Hospital, Kobe, Japan

4. Hyogo Medical Examiner's Office, Kobe, Japan

5. Hyogo Emergency Medical Center, Kobe, Japan

6. Tokyo Medical University, Shinjuku, Japan

7. Kyowa Mariner Hospital, Nishinomiya, Japan

Introduction: In 2006, Japan DMORT was established by physicians, nurses, forensic pathologists, social workers, and a journalist (inspired by a major train crash in the previous year) to provide mental support to disaster victims' families who had not received care. However, disaster victims' identification and care of the families were monopolized by police in Japan. Also, our 'study group' status confused people who were affected by disasters.

Aim: To describe the development and future challenges of our association.

Methods: We developed our policy to focus on mental support through various activities such as the 11 closed seminars with disaster victims' families, 21 training courses for disaster responders, and several workshops in medical or nursing conferences. In the Christchurch Earthquake, NZ (2011), with young Japanese casualties in a collapsed building, our core member reported the needs of families' mental support, which showed the validity of our policy.

Results: In the Great East Japan Earthquake (2011), we distributed mental health care manuals for disaster responders. In the landslides in Izu Oshima Island (2013), 3 members supported victims' families through the town office. In the Kumamoto Earthquake (2016), two members made grief work on families of 17 victims at the prefectural police academy. These activities convinced the police of the need for medi$\mathrm{cal} /$ mental support and ourselves of the necessity for legal status. In 2017, we reorganized our association into an incorporated society. We also became official members of crime/disaster victims support liaison councils of two prefectures among 47 in Japan. In 2018, official agreements were made with the Hyogo prefectural police. But in the Heavy Rains and Flooding of July and in the Hokkaido Eastern Iburi Earthquake of September, the local police did not agree to accept us.

Discussion: Official collaboration with police is essential nationwide in Japan. Further relief activities are expected.

Prehosp Disaster Med 2019;34(Suppl. 1):s117

doi:10.1017/S1049023X19002504 